\title{
The Endometrium Biopsy and Hystero-Laparoscopy in Evaluation of Women's Infertility. A Prospective Study in Algeria
}

\author{
Nassima Cheheb1,2*, Abdenacer Tou'2,3,4, Fadl Allah Abou-Bekr ${ }^{4,5}$, Mohammed Lebid 2,3 \\ ${ }^{1}$ Department of Biology, Faculty of Nature and Life Sciences, University of Sidi Bel Abbes, Sidi Bel Abbes, Algeria \\ ${ }^{2}$ Laboratory of Environmental and Cancer Research (LECR), University of Sidi Bel Abbes, Sidi Bel Abbes, Algeria \\ ${ }^{3}$ Service of Pathology, University Hospital of Sidi Bel Abbes, Sidi Bel Abbes, Algeria \\ ${ }^{4}$ Faculty of Medical Sciences, University of Sidi Bel Abbes, Sidi Bel Abbes, Algeria \\ ${ }^{5}$ Service of Obstetrics and Gynecology, University Hospital of Sidi Bel Abbes, Sidi Bel Abbes, Algeria \\ Email: *chehebnassima@outlook.com
}

Received 4 February 2015; accepted 15 March 2016; published 18 March 2016

Copyright (C) 2016 by authors and Scientific Research Publishing Inc.

This work is licensed under the Creative Commons Attribution International License (CC BY).

http://creativecommons.org/licenses/by/4.0/

(c) (i) Open Access

\section{Abstract}

Female infertility is considered as a real obstacle to the development of a couple who cannot conceive in a natural way. The aim of this study is to evaluate female infertility using two complementary methods of exploration: hystero-laparoscopy and endometrial biopsy, to compare histopathological data with those of hystero-laparoscopy findings in the same patients, and finally assess the interest to couple both methods to detect a greater number of pathologies. Our prospective study included 64 patients aged 20 - 43 years with primary or secondary infertility for a period of 3 years ranging from 2012 to 2015 at obstetrics and gynecology department in which all patients were admitted to a hysteroscopy followed by laparoscopy. Endometrial biopsy curettage was performed and sent to the Pathological Anatomy Department for a histopathological study. On 64 infertile women explored, no pathologies were findings in 20 patients $(31.3 \%)$ to the biopsy and 27 patients $(42.2 \%)$ by hysteroscopy-laparoscopy. Histopathological study was in favor of dysfunctional endometrium (50\%) followed by hyperplasia (10.9\%). The lesions findings in the hystero-laparoscopy were in the first place uterine $(18.8 \%)$ followed by equally between tubal and endometrial pathologies $(\mathbf{1 0 . 9 \% )}$. Associated diseases affecting the same organs or more were recorded with a percentage of $7.8 \%$. The two methods have been shown effective and the most of common pathologies findings were uterine and endometrial. We concluded that the endometrial biopsy was more decisive in the exploration of endometrium pathologies while hystero-laparos-

\footnotetext{
"Corresponding author.
} 
copy is more sensitive for the exploration of uterine, tubal and ovarian pathologies. Each method taken individually was revealed incomplete. It is more interesting to systematically couple the histology with endoscopic examination in order to detect a greater number of pathologies.

\section{Keywords}

Female Infertility, Endometrial Biopsy, Hystero-Laparoscopy

\section{Introduction}

Infertility is defined as the inability for a couple to conceive a pregnancy following 1 year of unprotected vaginal intercourse [1]. The incidence of female infertility is rising and varies from $10 \%$ to 20\% [2]. Primary infertility fails to conceive at all whereas secondary infertility fails to conceive after having borne a child or abortion [3]. During the breeding period, the endometrium undergoes morphological and physiological changes characterized by growth, differentiation and secretion in the absence of fertilization, menstruation and regeneration. These cyclic changes are intended to create a suitable environment for implantation [4]. The factors involved in embryo implantation are embryonic quality, endometrial receptivity, and the integrity of the uterine cavity. One of the requirements of the success of implantation is the anatomical and functional integrity of the uterine cavity [5] [6]. Benign abnormalities are thought to be associated with poor endometrial receptivity and necessitate evaluation of the uterine cavity [7]. Evaluation of the uterine cavity is a basic step in female infertility workup [8]. Today, hysteroscopy is considered the gold standard for evaluation the uterine cavity, and due to improved endoscopic developments, can be performed reliably and safely as an office procedure [9]. Laparoscopy and hysteroscopy are diagnostic and therapeutic procedures. If pathology is discovered, it can often be treated immediately. We consider combined laparoscopy and hysteroscopy to be one of the most important procedures in the evaluation of female infertility [10]. If hysteroscopy provides a macroscopic description of the endometrium, the ideal is to couple an examination to endometrial sampling well tolerated and representative, to correlate the endoscopic histological data [11]. The endometrial biopsy is an essential step in the investigation of infertile women. Many authors have concluded that endometrial biopsy is a safe, reproducible and adequate means of providing histological evidence of normal endometrial development [12].

\section{Patients and Methods}

Our prospective study was conducted over a period of 03 years from December 2012 to June 2015 in Hospital-Center University of the Wilaya of Sidi Bel Abbes in Algeria "service of obstetrics and gynecology". 64 patients were selected for the study. It was included in our study only patients with indication as a primary or secondary infertility, aged 20 - 43 years who have tried to conceive for at least one year before. An interview was conducted on each patient admitted for diagnostic hysteroscopy followed by laparoscopy during hospitalization preceding each intervention that aims to gather the necessary clinical information. All patients were admitted for a hysteroscopy to directly visualize the cavity and uterine lining followed by laparoscopy for further exploration of the fallopian tubes, uterus and pelvis and mainly for its therapeutic value. Tubal patency was verified in all patients by a test with methylene blue. Endometrial biopsy curettage were performed for each patient during the same intervention even for those with no particular signs has endoscopic review for the diagnosis of endometrial pathology; and finally to correlate endoscopic aspects findings with histological data. These biopsies were addressed at the anatomical pathology department for a histopathologic study when many parameters were evaluated: appearance of the glands; stroma; vessels and other anomalies findings. The value of biopsies based on the choice of the biopsy area and good preservation of the fragments. He was excluded from our study all insufficient or hemorrhagic samples. The diagnoses were confirmed by pathology reports. The data collected during this study was conducted by statistics SPSS (Version 20). The statistical analysis of variance (ANOVA Matrix) and the standard deviation were used to deepen the degree of homogeneity of each method individually. By against the Kappa statistics was used to evaluate the correlation between the biopsy and hystero-laparoscopy results. 


\section{Results}

In this present study we noted a maximum of patients (59.4\%) were age $<35$ years and (40.6\%) were age $\geq 35$ years. with an average age of 33 years and the extremes of $23-43$ years. We recorded (71.9\%) primary infertility and $28.1 \%$ secondary infertility (Table 1 ).

Deling the 64 patients explored; the endometrial biopsy may reveals normal endometrium in 20 patients (31.3\%). The most of histopathological lesions observed were in the first place dysfunctional endometrium (50\%). The relevant lesions of this type was the endometrium by estrogen deficiency (21.9\%) followed equalling by endometrium with a progesterone deficiency (12.5\%) and dyshormonal endometrium with signs of progesteronique impregnation (12.5\%), the endometrium with oestroprogestatif deficit was detected in only 2 cases (3.1\%). In a second time, the lesions were in favor of hyperplasia (10.9\%): there were 6 cases of simple hyperplasia without atypia and 1 case of complexe hyperplasia with atypia. Only 3 cases (4.7\%) of polyps were detected by biopsy. The results were considered significant for $p<0.05$ (Table 2).

Table 1. Demographic characteristics of infertile women’s group.

\begin{tabular}{ccc}
\hline Number and percentage of women's group & $\mathbf{6 4}$ & $\mathbf{1 0 0 \%}$ \\
\hline Age & & $59.4 \%$ \\
$<35$ years & 38 & $40.6 \%$ \\
Type of infertility & 26 & $71.9 \%$ \\
Primary infertility & 46 & $28.1 \%$ \\
Secondary infertility & 18 & \\
\hline
\end{tabular}

Table 2. Aspects findings by biopsy in infertile women's group.

\begin{tabular}{|c|c|c|c|c|c|}
\hline Aspects findings by endometrial biopsy & Number & Percentage (\%) & $\bar{x}$ & $\boldsymbol{V}$ & $\sigma$ \\
\hline Dysfonctional endometrium & 32 & $50 \%$ & 16.02 & 0.0059 & 0.077 \\
\hline Endometrium by estrogen deficiency & 14 & $21.9 \%$ & & & \\
\hline Endometrium with a progesterone deficiency & 8 & $12.5 \%$ & & & \\
\hline $\begin{array}{l}\text { Dyshormonal endometrium with signs of } \\
\text { progesteronique impregnation }\end{array}$ & 8 & $12.5 \%$ & & & \\
\hline Endometrium with oestroprogestatif deficit & 2 & $3.1 \%$ & & & \\
\hline Endometrial hyperplasia & 7 & $10.9 \%$ & 8.29 & 0.0030 & 0.055 \\
\hline Simple hyperplasia without atypia & 6 & $9.4 \%$ & & & \\
\hline Complexe hyperplasia with atypia & 1 & $1.6 \%$ & & & \\
\hline Endometrial polyp & 3 & $4.7 \%$ & 4.70 & 0.5685 & 0.754 \\
\hline Other patholgies findings & 2 & $3.1 \%$ & 1.60 & 0.4998 & 0.707 \\
\hline Endometrium after abortion & 1 & $1.6 \%$ & & & \\
\hline Atypia of Arias Stella & 1 & $1.6 \%$ & & & \\
\hline Normal endometrium & 20 & $31.3 \%$ & 31.30 & 0.0501 & 0.224 \\
\hline Total & 64 & $100 \%$ & & & \\
\hline
\end{tabular}

$\bar{x}$ : average, $V$ : variance, $\sigma$ : standard deviation.

\begin{tabular}{|c|c|c|c|c|c|c|}
\hline \multicolumn{7}{|c|}{ ANOVA Matrix } \\
\hline Source & SC & $\mathrm{dl}$ & $\mathrm{CM}$ & $\mathrm{F}$ & $p$ & Reported \\
\hline SCI & 5332.46 & 4 & 1333.11 & 28,169.35 & 0.0000 & $p<0.05$ \\
\hline SCR & 2.79 & 59 & 0.05 & & & \\
\hline Total & 5335.25 & 63 & 1333.16 & & & \\
\hline \multicolumn{2}{|c|}{ State Square } & \multicolumn{2}{|l|}{$100 \%$} & $\mathrm{~s} \max / \mathrm{s}$ & \multicolumn{2}{|r|}{13.71} \\
\hline \multicolumn{2}{|c|}{ Omega Square } & \multicolumn{2}{|l|}{$100 \%$} & $\mathrm{v} \max / \mathrm{v}$ & \multicolumn{2}{|r|}{187.94} \\
\hline
\end{tabular}


The hystero-laparoscopy showed 27 patients (42.2\%) with no anomalies. The most of lesions founded in this exam were uterine (18.8\%) followed by tubal (10.9\%), endometrial (10.9\%) and ovarian (7.8\%) pathologies. We have noted the existence of association of multiple diseases with a percentage of (7.81\%) with a large number of uterine diseases associated with endometrial diseases ( 3 cases). The most uterine pathology observed was the myoma (9.4\%), tubal by hydrosalpinx (7.8\%), endometrial by hyperplasia (7.8\%) and ovarian pathologies which were exclusively represented by ovarian dystrophies (7.8\%). The results were considered significant for $p<$ 0.05 (Table 3).

In our prospective study, all of infertile women's were explored systematically with two methods of evaluation, hystero-laparoscopy and biopsy. The two methods have shown effective because the large number of pathologies were detected; by biopsy (68.7\%) and hystero-laparoscopy (57.8\%). The most of common pathologies findings were uterine and endometrial. The biopsy was more decisive in the exploration of the pathologies of the endometrium while hystero-laparoscopy is more sensitive for the exploration of uterine, tubal and ovarian pathologies. The results were considered not significant for $p>0.05$ and was confirmed by Kappa $(k=0.0113)$ (Table 4).

When we compare the hystero-laparoscopy report with other results findings in the biopsy, we showed 15 women with a normal hystero-laparoscopy and biopsy enregistred functional lesions and 1 case of hyperplasia.

Table 3. Aspects findings by hystero-laparoscopy in infertile women's group.

\begin{tabular}{|c|c|c|c|c|c|}
\hline Aspects findings by hystero-laparoscopy & Number & Percentage (\%) & $\bar{x}$ & $\boldsymbol{V}$ & $\sigma$ \\
\hline Uterine pathology & 12 & $18.8 \%$ & 5.76 & 0.00097 & 0.0312 \\
\hline Myoma & 6 & $9.4 \%$ & & & \\
\hline Synechia & 2 & $3.1 \%$ & & & \\
\hline Polyp & 2 & $3.1 \%$ & & & \\
\hline Malformation cavity & 2 & $3.1 \%$ & & & \\
\hline Tubal pathology (tubal obstruction) & 7 & $10.9 \%$ & 5.80 & 0.00120 & 0.036 \\
\hline Hydrosalpinx & 5 & $7.8 \%$ & & & \\
\hline Salpingitis & 1 & $1.6 \%$ & & & \\
\hline Tubal phimosis & 1 & $1.6 \%$ & & & \\
\hline Endometrium pathology & 7 & $10.9 \%$ & 6.46 & 0.00100 & 0.0331 \\
\hline Endometrial hyperplasia & 5 & $7.8 \%$ & & & \\
\hline Endometrial atrophy & 2 & $3.1 \%$ & & & \\
\hline Ovarian pathology & 5 & $7.8 \%$ & 7.80 & 0.19980 & 0.447 \\
\hline Multiple pathologies findings & 5 & $7.8 \%$ & 5.50 & 0.00005 & 0.007 \\
\hline Endometrial hyperplasia + Polyp & 2 & $3.1 \%$ & & & \\
\hline Endometrial hyperplasia + Myoma & 1 & $1.6 \%$ & & & \\
\hline Endometrial hyperplasia + Ovarian dystrophy + Hydrosalpinx & 1 & $1.6 \%$ & & & \\
\hline Myoma + Synechia + Hydrosalpinx & 1 & $1.6 \%$ & & & \\
\hline Other pathologies findings (metaplasia osteoma) & 1 & $1.6 \%$ & 1.60 & - & - \\
\hline Normal endometrium & 27 & $42.2 \%$ & 42.20 & 0.03680 & 0.192 \\
\hline Total & 64 & $100 \%$ & & & \\
\hline
\end{tabular}

$\bar{x}$ : average, $V$ : variance, $\sigma$ : standard deviation.

\begin{tabular}{|c|c|c|c|c|c|c|}
\hline \multicolumn{7}{|c|}{ ANOVA Matrix } \\
\hline Source & SC & dl & $\mathrm{CM}$ & $\mathrm{F}$ & $p$ & Reported \\
\hline SCI & $20,463.81$ & 6 & 3410.63 & $76,035.69$ & 0.0000 & $p<0.05$ \\
\hline SCR & 2.56 & 57 & 0.04 & & & \\
\hline Total & $20,466.36$ & 63 & 3410.68 & & & \\
\hline State Square & & $100 \%$ & & $\mathrm{~s} \max / \mathrm{s} \min$ & & 142.86 \\
\hline Omega Square & & $100 \%$ & & $\mathrm{v} \max / \mathrm{v} \min$ & & $20,408.16$ \\
\hline
\end{tabular}


There were 7 women who had a normal biopsy and hystero-laparoscopy releved uterine disease (myoma and polyp), tubal disease (hydrosalpinx and salpingitis) and 1 cases of hyperplasia. The normal diagnostics was found in hystero-laparoscopy and confirmed by biopsy in only 13 cases (Table 5).

\section{Discussion}

Between $10 \%$ and $15 \%$ of Algerian couples legally marry, suffer from the problem of infertility. The Ministry of health quantifies the rate of 300,000 sterile couples. Sterility is experienced as a real drama for the spouses who are unable to conceive a child naturally way [13]. The woman's age is an important factor, due to the significant decrease in fertility after the age of 35 years, much aggravated after 40 years [14]. In our study the average age of patients was 33 years. Our results can be explained by the average age of wedding that is about 30 years for women in Algeria. We recorded most of patients (71.9\%) with primary infertility, these results are similar to those of Sahu et al. study reporting (71.6\%) with primary infertility [9].

Our study aimed to evaluate infertility look using two diagnostic methods, hystero-laparoscopy andendometrial biopsy. In purpose our goal has been achieved for the majority of our patients had both a pathology in

Table 4. Recapitulative of pathologies findings with biopsy and hystero-laparoscopy exam.

\begin{tabular}{ccccc}
\hline \multirow{2}{*}{ Common pathologies findings } & \multicolumn{2}{c}{ Biopsy recorded } & \multicolumn{2}{c}{ Hystero-laparoscopy recorded } \\
\cline { 2 - 5 } & Number & Percentage (\%) & Number & Percentage (\%) \\
\hline Normal endometrium & $\mathbf{2 0}$ & $\mathbf{3 1 . 3 \%}$ & $\mathbf{2 7}$ & $\mathbf{4 2 . 2 \%}$ \\
Uterine pathologies & 3 & $4.7 \%$ & 12 & $18.8 \%$ \\
Endometrial pathologies & 39 & $60.9 \%$ & 7 & $10.9 \%$ \\
Tubal pathologies & & & 5 & $7.9 \%$ \\
Ovarian pathologies & & 5 & $7.8 \%$ \\
Multiple pathologies findings & 2 & $3.1 \%$ & $\mathbf{6 4}$ & $\mathbf{1 0 0 \%}$ \\
Other pathologies findings & $\mathbf{1 0 0 \%}$ & & \\
Total & $\mathbf{6 4}$ & & \\
$k=0.0113$ & & & \\
\hline
\end{tabular}

Table 5. Comparison of normal/abnormal hystero-laparoscopy report with others results findings in the biopsy.

\begin{tabular}{|c|c|c|}
\hline Hystero-laparoscopy recorded & Endometrial biopsy recorded & Number \\
\hline Normal & Normal & 13 \\
\hline Normal & Atrophic endometrium by estrogen deficiency & 8 \\
\hline Normal & Dyshormonal endometrium with signs of progesteronique impregnation & 3 \\
\hline Normal & Simple hyperplasia & 2 \\
\hline Normal & Endometrium after abortion & 1 \\
\hline Normal & Atypia of Arias Stella & 1 \\
\hline Myoma & Normal & 1 \\
\hline Polyp & Normal & 1 \\
\hline Malformation cavity & Normal & 1 \\
\hline Hydrosalpinx & Normal & 2 \\
\hline Salpingitis & Normal & 1 \\
\hline Simple hyperplasia & Normal & 1 \\
\hline \multicolumn{2}{|r|}{ Total } & 35 \\
\hline
\end{tabular}


hystero-laparoscopy (57.8\%) and biopsy (68.7\%). Both methods were effective. Hysteroscopy is the gold standard procedure for uterine cavity exploration [7]. Diagnostic hysteroscopy should be included routinely in the work-up of invasive examination for infertile patients [10]. The role of hysteroscopy in infertility investigation is to detect possible changes that could interfere with implantation or growth, or both, of the conceptus, and to evaluate the benefit of different treatment modalities in restoring a normal endometrial environment [9]. The value of hysteroscopy is limited for detection of subtle and/or local endometrial changes which has not produced a macroscopic finding. Endometrial biopsy is employed to diagnose cellular pathologies [15].

\subsection{Endometrial Pathologies}

Endometrial receptivity is defined as a temporary unique sequence of factors that make the endometrium receptive to the embryonic implantation. It is the window of time when the uterine environment is conductive to blastocyst acceptance and subsequent implantation [16]. The endometrium thickens during the proliferative phase of the menstrual cycle in response to estrogen secretion by maturing follicles. The thickened endometrium provides a site for attachment, and is the source of nourishment for an implanting embryo during its first few weeks, until the placenta develops [17]. The endometrium undergoes precisely defined morphological changes until a receptive endometrium is developed. These morphological changes were described as early as 1950 by Noyes, Hertig and Rock and occur under the control of the sexual steroid hormones, estrogen and progesterone [18]. The endometrial pathology is a common condition, it can be asymptomatic and discovered incidentally during an ultrasound examination, the cause of primary or secondary infertility [19]. Most endometrial pathologies implicated in infertility result in both structural and functional impairments [20]. The endometrial biopsy remains the examination of choice in the diagnosis of lesions of the endometrial. Histology is still important in the treatment of endometrial pathology [21].

Dysfunctional endometrium: Dysfunctional endometrium means a discordant maturation between endometrium and hormonal cycle, or a focal discordance with focal areas in various phases of endometrial cycle at the same time [22]. In our study endometrial pathologies were founded with the percentage of (60.9\%). The most of histopathological aspects enregistred were dysfunctional endometrium (50\%) with a large number of estrogen and progesterone deficiency. This results are similar to those of Sakande et al. [23] where the dysfunctional endometrium is the largest anomaly disorders and those of Sando et al. [21] where all biopsies indicated that infertility have shown dysfunctional lesions of endometrium. Hystero-laparoscopy was not sensitive of dysfunctional endometrium. The endometrial biopsy remains the best performing hysteroscopy in the diagnosis of functional disorders that can hinder female fertility and cause infertility.

Endometrial hyperplasia: We noted patients (10.9\%) with hyperplasia finding by biopsy, hystero-laparoscopy enregistred (7.8\%) of hyperplasia and 3 cases of hyperplasia associated with uterine deseases. But unlike hystero-laparoscopy, the biopsy allowed to classify these hyperplasia, we notes 6 cases of simple hyperplasia without atypia and 1 case of complex hyperplasia with atypia. Study of Kumar et al. [24] showed 3 cases of endometrial hyperplasia: 2 were of simple hyperplasia and 1 was atypical hyperplasia detected by hysteroscopy and confirmed by histopathological examination, Manjunath et al. [3] detected 5 cases (5.5\%) of hyperplasia by biopsy and Siam [7] showed $2.1 \%$ of hyperplasia by hysteroscopy. The hysteroscopy has identified this hyperplasia but could not give classification. It is also an excellent indication and can be easily diagnosed [25]. The hysteroscopy is an essential consideration in the management of hyperplasia. It directs the diagnosis and guides biopsy. Only histological examination allows the diagnosis of endometrial hyperplasia and his type, according to the architectural and cytological criteria [26]. In this study the two methods of exploration: hystero-laparoscopy and endometrial biopsy were been efficient in the diagnostics of hyperplasia but the biopsy was more determinate for the classification of this hyperplasia.

\subsection{Uterine Pathologies}

Abnormalities of the uterine cavity are responsible for $10 \%$ to $15 \%$ of infertility. Hysteroscopy is a test that directly examines the cavity and uterine lining posing diagnosis of intra cavitary lesions (synechiae, polyps, myoma) and uterine defects [27].

Polyps: It has not been proved whether polyps are more common in infertile women compared with non-infertile women. The prevalence of polyps in the infertile population has not been studied in detail [28]. In this present study, there were 3 patients with Polyp detected by biopsy and 4 patients by hystero-laparoscopy: 2 
woumen with polyp and 2 women with polyp associated with hyperplasia. In comparative study of Sakandé et al. [23] and Manjunath et al. [3] polyp were reported by biopsy in only one case, and in other study of Sahu et al. [9] and Siam S [7] enregistred by hysteroscopy respectively 2 and 7 cases of polyp. Nevertheless, Godinjak et al. [10] found polyp in most common lesion by hysteroscopy. It can be concluded that hystero-laparoscopy and biopsy have the same sensitive in the diagnostic of polyps. Endometrial biopsy is inaccurate in diagnosing endometrial polyps. Hysteroscopy with guided biopsy is the most common comparator for other techniques to diagnose polyps [29].

Myoma: The greater part of hysteroscopical aspects observed were uterin (18.8\%). Most uterine pathologies implicated in infertility were myomas (9.4\%). The degree to which fibroids contribute to infertility is controversial. Fibroids were implicatd as the sole factor of infertility in $<10 \%$ [30]. The mechanisms by which myomas may affect reproductive outcome are as follows [31]. Their participation in the process of infertility is linked to their location [32]. Our results are far from those of Barati et al. [20] and those of Siam [7] when the most uterine pathologies findings by hysteroscopy were polyp.

Synechia: The causal relationship between synechia and infertility is not clearly established [33]. In this study 2 cases of synechia were detected and 1case presented in the same time synechia and myoma. Hysteroscopy can see the synechia, to assess the size, topography, thickness, and also to do the treatment [34].

Malformation cavity: Anomalies of the uterus are considered to be one of the reasons for infertility in women [10]. The prevalence of uterine malformation is estimated to be $6.7 \%$ in general population, $7.3 \%$ in infertile women, and $16 \%$ in women with a history of recurrent miscarriages [2]. We noted only 2 cases (3.1\%) of malformation cavity in our study. The incidence of uterine malformation in other series of infertile patients varies between $1 \%$ and $26 \%$, with a mean incidence of $3.4 \%$ [9]. In this study intrauterines abnormalities (myoma, synechia and malformation cavity) were findings only with hystero-laparoscopy.

\subsection{Tubal Pathologies}

Tubal dysfunction is responsible for approximately $30 \%$ of infertility cases. Tests to determine if the tubes are open and undamaged are an important part of the infertility workup [35]. In our study all our patients have benefited from a hysteroscopy followed by laparoscopy. Tubal patency was verified in all patients by a test of methylene blue. The tubal pathology was found after uterine pathology in (10.9\%) cases. The major cause was the hydrosalpinx (7.8\%) followed by a case of pelvic inflammatory disease and one case of tubal phemosis. These diseases had as consequence tubal impermeability. Laparoscopy allows direct visualization of the fallopian tubes, uterus and the pelvis. It has a diagnostic and possibly therapeutic interest. It is considered by most authors as the "gold standard" in the exploration of the pelvis in cases of infertility [36].

\subsection{Ovarian Pathologies}

Infertility resulting from ovarian dysfunction may be due to absence of eggs in the ovaries or due to a complete blockage of the ovaries [37]. Ovarian pathologies were funding in (7.8\%) of cases exclusively represented by ovarian dystrophies.

\subsection{Other Pathologies Detected}

During our exploration cavity, one case of metaplasia osteoma was detected during hystero-laparoscopy. Sala et al. also take up this case in their study group [6]. Histopathological study has identified one case of endometrium post-abortion and one case of endometrial with atypia of Arias Stella, reflecting pregnancy gone unnoticed.

\section{Conclusion}

During our study endometrial biopsy was more sensitive than hystero-laparoscopy in the diagnosis of diseases of the endometrium, and against hystero-laparoscopy was more effective in the exploration of intrauterine, tubal, and ovarian abnormalities. We can deduce that it is more interesting to systematically couple the histology with endoscopic examination to identify a larger number of diseases. Each method taken individually remains incomplete. 


\section{Acknowledgements}

The authors thank everyone who contributed to this study, including service mark of Pathology and GynecologyObstetrics of the University Hospital of Sidi Bel Abbes.

\section{References}

[1] Phillips, C.H., Benson, C.B., Ginsburg, E.S. and Frates, M.C. (2015) Comparaison of Uterine and Tubal Pathology by Transvaginal Sonography, Hysterosalpingography, and Hysteroscopie in Female Patients with Infertility. Fertility Research and Practice, 1, 1-6. http://dx.doi.org/10.1186/s40738-015-0012-3

[2] Moghadam, D.A., Delpisheh, A. and Khosravi, A. (2013) Epidemiology of Female Infertility; A Review of Literature. Biosciences Biotechnology Research ASIA, 10, 559-567. http://dx.doi.org/10.13005/bbra/1165

[3] Girish, C.J. and Manjunath, M.L. (2011) Morphological Patterns of Endometrium in Infertile Woman-A Prospective Study. International Journal of Applied Biology and Pharmaceutical Technology, 2, 512-520.

[4] Bergeron, C. (2006) Histologie et physiologie de l’endomètre normal. Encyclopédie Médico-chirurgicale, Gynécologie. Elsevier, SAS, Paris, 31-L-10.

[5] Ait Benkaddour, Y., Aboulfalah, A. and Abbassi, H. (2009) Place de l’hystéroscopie en assistance médicale à la procréation. Médecine de la Reproduction, Gynécologie Endocrinologie, 11, 294-301.

[6] Ait Benkaddour, Y., Gervaise, A. And Fernandez, H. (2010) Exploration de la cavité utérine dans le bilan d'infertilité: Quel examen choisir? Journal de Gynécologie Obstétrique et Biologie de la Reproduction, 39, 606-613. http://dx.doi.org/10.1016/j.jgyn.2010.08.004

[7] Siam, S. (2014) Role of Office Hysteroscopy in the Evaluation of Infertile Women after Controlled Ovarian Stimulation/ Intra Uterine Insemination Failure. Middle East Fertility Society Journal, 19, 239-242. http://dx.doi.org/10.1016/j.mefs.2013.05.008

[8] Carneiro, M.M. (2014) Wat Is the Role of Hysteroscopic Surgery in the Management of Female Infertility? A Review of the Literature. Surgery Research and Practice, 1, 2-6.

[9] Sahu, L., Tempe, A. and Gupta, S. (2012) Hysteroscopic Evaluation in Infertile Patients: A Prospective Study. International Journal of Reproduction, Contraception, Obstetrics and Gynecology, 1, 37-41. http://dx.doi.org/10.5455/2320-1770.ijrcog001512

[10] Godinjak, Z. and Idrizbegovic, E. (2008) Should Diagnostic Hysteroscopy Be a Routine Procedure during Diagnostic Laparoscopy in Infertile Women? Bosnian Journal of Basic Medical Sciences, 8, 44-47.

[11] Agostini, A., Cravello, L., Rojat-Habib, M.-C., Amabile-Boulat, J., Roger, V., Bretelle, F. and Blanc, B. (1999) Évaluation de deux méthodes de prélèvement endométriale au cours de l’hystéroscopie diagnostique. Journal de Gynécologie Obstétrique et de Biologie de la Reproduction, 28, 433-437.

[12] Sahmay, S., Oral, E., Saridogan, E., Senturk, L. and Atasu, T. (1995) Endometrial Biopsy Finding in Infertility: Analysis of 12,949 Cases. International Journal of Fertility and Menopausal Studies, 40, 316-321.

[13] Rédaction nationale (2010) La stérilité, un malheur pour le couple. Journal Liberté (quotidien d'information). http://www.liberte-algerie.com/actualite/la-sterilite-un-malheur-pour-le-couple-80163

[14] Maubon, A., Pouquet, M., Piver, P., Mazet, N., Viala-Trentini, M. and Rouanet, J.P. (2008) Imagerie de l’infertilité féminine. Journal de Radiologie, 89, 172-84. http://dx.doi.org/10.1016/S0221-0363(08)70391-3

[15] Kuçuk, T. and Safali, M. (2008) “Chromohysteroscopy” for Evaluation of Endometrium in Recurrent in Vitro Fertilization Failure. Journal of Assisted Reproduction and Genetics, 25, 79-82. http://dx.doi.org/10.1007/s10815-007-9196-8

[16] Aboubakr, M.E. and Gamal, I.A.E. (2004) Endometrial Receptivity. Middle East Fertility Society, 9, 10-24.

[17] Richter, K.S., Bugge, K.R., Bromer, J.G. and Levy, M.J. (2007) Relationship between Endometrial Thickness and Embryo Implantation, Based on 1,294 Cycles of in Vitro Fertilization with Transfer of Two Blastocyst-Stage Embryos. Fertility and Sterility, 87, 53-59. http://dx.doi.org/10.1016/j.fertnstert.2006.05.064

[18] Strowitzki, T., Germeyer, A., Popovici, R. and Von Wolff, M. (2006) The Human Endometrium as a Fertility- Determining Factor. Human Reproduction Update, 12, 617-630. http://humupd.oxfordjournals.org http://dx.doi.org/10.1093/humupd/dml033

[19] Lemercier, E., Genevois, A., Dacher, J.N., Benozio, M., Descargues, G. and Marpeau, L. (2000) L’endomètre: Quelle imagerie ? Journal de Radiologie, 81, 1845-1855.

[20] Barati, M., Zargar, M., Masihi, S., Borzoo, L. and Cheraghian, B. (2009) Office Hysteroscopy in Infertility. International Journal of Fertility and Sterility, 3, 17-20.

[21] Sando, Z., Fouogue, J.T., Fouélifack, F.Y., Mpay, S.M. and Mboudou, E.T. (2013) Indications et aspects histopa-tho- 
logiques des biopsies de l'endomètre à l’Hôpital Gynéco-Obstétrique et Pédiatrique de Yaoundé (Cameroun). African Journal of Pathology and Microbiology, 2, Article ID: 235694. http://dx.doi.org/10.4303/ajpm/235694

[22] Elbareg, A.M., Elmahashi, M.O. and Essadi, F.M. (2015) Evaluation of Intrauterine Pathology: Efficacy of Diagnostic Hysteroscopy in Comparaison to Histopathological Examination. Reproductive System \& Sexual Disorders, 4, 149. http://dx.doi.org/10.4172/2161-038X.1000149

[23] Sankandé, B., Lankoandé, J., Ouattara, T., Ouédraogo, A., Ouédraogo, C., Koné, B. and Soudré, B.R. (1998) Les biopsies de l'endomètre au centre hospitalier national Yalgaddo Ouedraogo de Ouagadougou (Burkina-Faso) Principales indications et aspects histologiques. Médecine d'Afrique Noire, 45, 118-121.

[24] Kumar, S., Awasthi, R.T and Gokhale, N. (2004) Assessment of Uterine Factor in Infertile Women: Hysterosal-Pingography vs Hysteroscopy. Medical Journal Armed Forces India, 60, 39-41. http://dx.doi.org/10.1016/S0377-1237(04)80156-4

[25] Philippe, C. and Charpin, E. (1992) Pathologie gynécologique et obstétrical. Edition Masson, Paris, 87.

[26] Brun, J.L., Cortez, A., Donnadieu, A.C., Bazot, M., Driguez, P.A. and Merviel, P. (2010) Pathologie tumorale endométriale bénigne et lésions frontières de l'endomètre. Encyclopédie Médico-chirurgicale, Gynécologie, Elsevier, SAS, Paris.

[27] Mechhal, M., Ben Aoun, J., Hcini, N., Gharsa, A., Oueslati, A., Binous, N. and Chaabene, N. (2012) Exploration de l'infertilité: Correlation hystérographie hystéroscopie. Tunisie Médicale, 90, 452-457.

[28] Silberstein, T., Saphier, O., Van Voorhis, B.J. and Plosker, S.M. (2006) Endometrial Polyps in Reproductive-Age Fertile and Infertile Women. The Israel Medical Association Journal, 8, 192-195.

[29] AAGL (2012) AAGL Practice Report: Practice Guidelines for the Diagnosis and Management of Endometrial Polyps The Journal of Minimally Invasive Gynecology, 19, 3-10. http://dx.doi.org/10.1016/j.jmig.2011.09.003

[30] Bajekal, N. and Li, T.C. (2000) Fibroids, Infertility and Pregnancy Wastage. Human Reproduction Update, 6, 614-620. http://dx.doi.org/10.1093/humupd/6.6.614

[31] Kolankaya, A. and Arici, A. (2006) Myomas and Assisted Reproductive Technologies: When and How to Act? Obstetrics \& Gynecology Clinics of North America, 33, 145-152. http://dx.doi.org/10.1016/j.ogc.2005.12.008

[32] Kouamé, N., N’goan-Domoua, A.M., Konan, N., Sétchéou, A., Tra-Bi, O., N’gbesso, R.D. and Kéita, A.K. (2012) Apport de l'échographie transvaginale dans la recherche étiologique de l'infertilité feminine à Abidjan (Côte d'Ivoire). African Journal of Reproductive Health, 16, 43-49.

[33] Khrouf, M., Morel, O., Hafiz, A., Chavatte-Palmer, P. and Fermandez, H. (2012) Evaluation of the Rabbit as Experimental Model for Human Uterine Synechia. Journal of Human Reproductive Sciences, 5, 175-180. http://dx.doi.org/10.4103/0974-1208.101017

[34] Pathologie bénigne de l'endomètre (2012) Gynécologie. Elsevier, Masson, SAS, Chapitre 8, 109-118.

[35] Allam, I.S., Rashed, A.M., Sweedan, K.H., El Bishry, G.A. and Ahmed, W.E. (2014) Role of Hysteroscopy in the Evaluation of Tubal Patency in Infertile Women. Middle East Fertility Society Journal, 19, 215-220. http://dx.doi.org/10.1016/j.mefs.2013.12.002

[36] Kehila, M., Ben Hmid, R., Ben Khedher, S., Mahjoub, S. and Bedis Channoufi, M. (2014) Concordance et apports de l'hystérosalpingographie et de la cœlioscopie dans l'exploration tubaire et pelvienne en cas d'infertilité. Pan African Medical Journal, 17, 126. http://dx.doi.org/10.11604/pamj.2014.17.126.3567

[37] Wasiu Eniola, O., Adebayo Adetola, A. and Taiwo Abayomi, B. (2012) A Review of Female Infertility; Important Etiological Factors and Management. Journal of Microbiology and Biotechnology Research, 2, 379-385. http://scholarsresearchlibrary.com/archive.html 